\title{
Americium preferred: Lanmodulin, a natural lanthanide-binding protein favors an actinide over lanthanides
}

Helena Singer ${ }^{[a] \dagger}{ }_{\dagger}, B j o ̈ r n ~ D r o b o t^{[b]} \dagger$, Cathleen Zeymer ${ }^{[c]}$, Robin Steudtner ${ }^{*[b]}$ and Lena J. Daumann ${ }^{*[a]}$

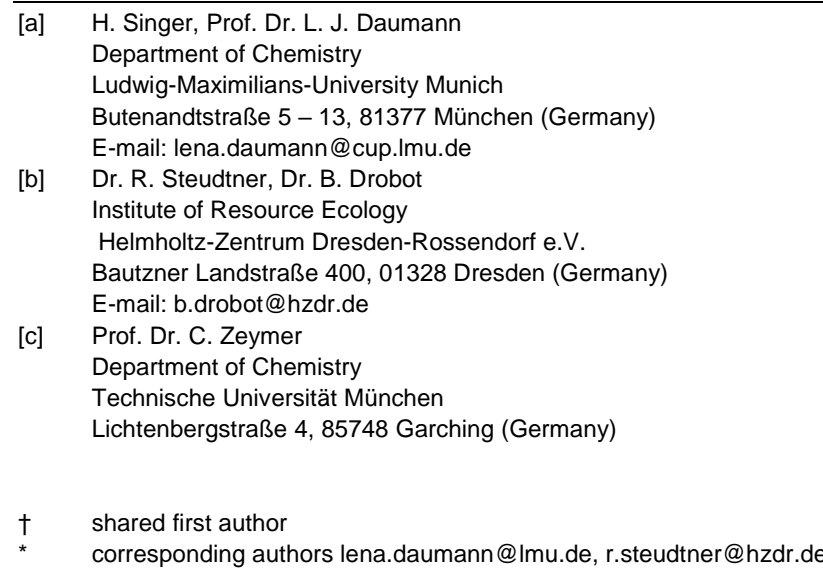

Keywords: europium, curium, $f$-block elements, TRLFS, separation, inter-metal competition studies, Lanmodulin

Abstract: The separation and recycling of lanthanides is an active area of research with a growing demand that calls for more environmentally friendly lanthanide sources. Likewise, the efficient and industrial separation of lanthanides from the minor actinides (Np, Am - Fm) is one of the key questions for closing the nuclear fuel cycle; reducing costs and increasing safety. With the advent of the field of lanthanide-dependent bacterial metabolism, bio-inspired applications are in reach. Here, we utilize the natural lanthanide chelator Lanmodulin and the luminescent probes $\mathrm{Eu}^{3+}$ and $\mathrm{Cm}^{3+}$ to investigate the inter-metal competition behavior of all lanthanides (except Pm) and four actinides (Np, Pu, Am, Cm) to Lanmodulin. Using time-resolved laser-induced fluorescence spectroscopy we show that Lanmodulin has the highest relative binding affinity to $\mathrm{Nd}^{3+}$ and $\mathrm{Eu}^{3+}$ among the lanthanide series. When equimolar mixtures of $\mathrm{Cm}^{3+}$ and $\mathrm{Am}^{3+}$ are added to Lanmodulin, Lanmodulin preferentially binds to $\mathrm{Am}^{3+}$ over $\mathrm{Cm}^{3+}$ whilst $\mathrm{Nd}^{3+}$ and $\mathrm{Cm}^{3+}$ bind with similar relative affinity. The results presented show that a natural lanthanide-binding protein can bind various actinides with high relative affinity, paving the way to bio-inspired separation applications. In addition, an easy and versatile method was developed, using the fluorescence properties of only two elements, Eu and $\mathrm{Cm}$, for inter-metal competition studies regarding lanthanides and selected actinides and their binding to biological molecules. 
Introduction: $f$-block elements have become indispensable components for modern day life and are found in all high technologies, medicine and agriculture earning them the name Vitamins of Modern Industry. ${ }^{[1]}$ Primary sources for lanthanides (Ln, or rare earth elements, REE, if Sc and $\mathrm{Y}$ are included) are carbonate minerals such as bastnaesite or the phosphate ores monazite or xenotime. ${ }^{[2]}$ Since only mixtures of REE are available from these natural sources, lavish separation processes with highly engineered ion-exchange and solvent extraction routes are required.[1a, 2a] These elaborate procedures are mainly driven by the strong resemblance in chemical properties (similar ionic radii, oxidation state +III) in the Ln series, which complicates the energy consuming separation and requires a large number

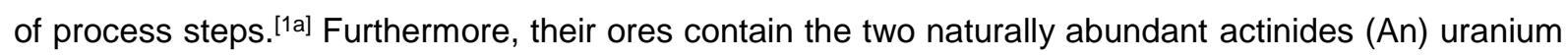
and thorium, generating a large amount of radioactive waste as by-products during REE mining. Considering the importance of REE for green energy resources and sustainable applications, a more environmentally friendly way would be recovering and recycling REE from end of life items (e.g. e-waste) or coal fly ashes. ${ }^{[3]}$ The separation of REE from actinides, as they occur together in mixtures in nuclear fuel cycles, is a similarly tricky endeavour and an active area of research. ${ }^{[4]}$ In addition, efficient chelators for the clean-up of radioactive environmental spills are desired.

Nature has designed several ligands and proteins for efficient metal binding, with siderophores at the forefront. Inspired by these natural chelators, such as enterobactin and deferoxamine, researchers have

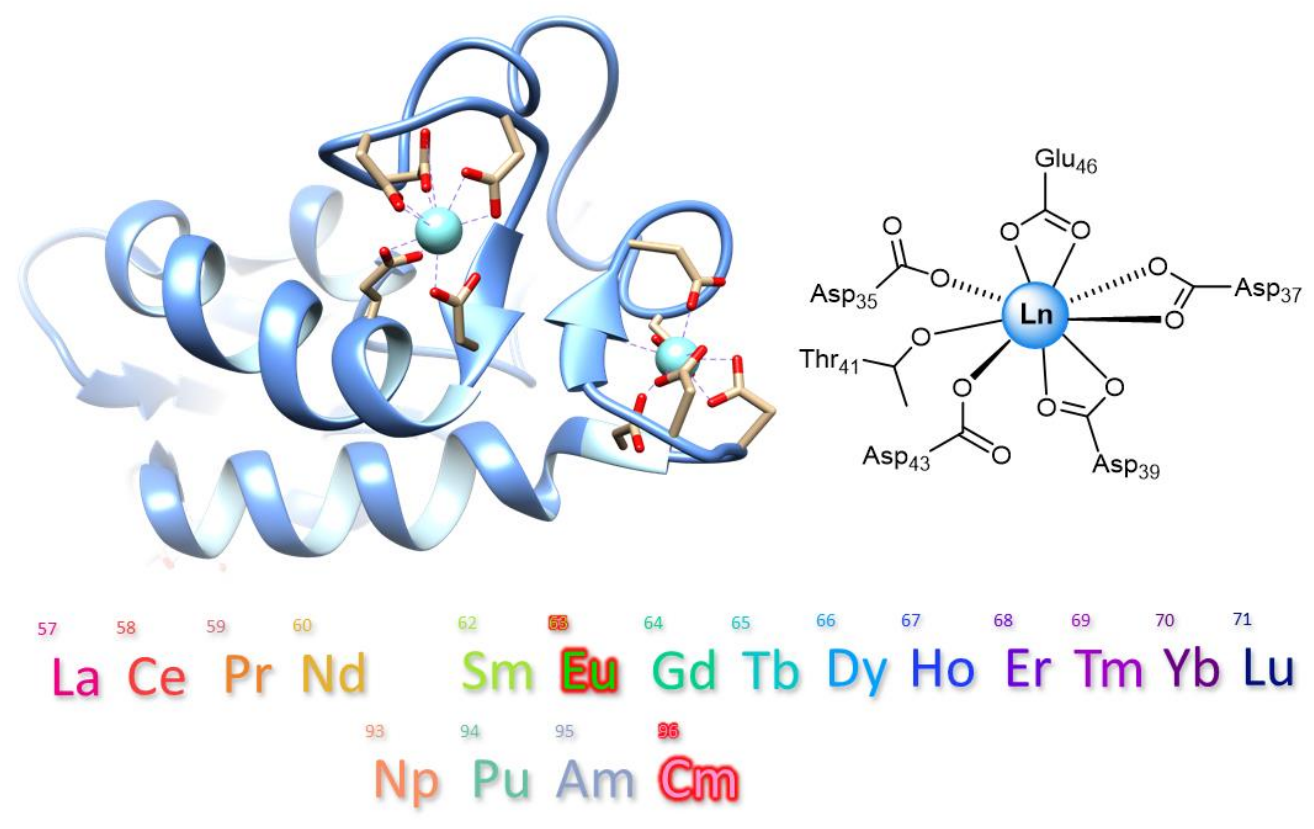

Figure 1. NMR-determined structure of Y-LanM with two of the high-affinity EF hands shown in more detail and close-up view of EF1. Below the $\mathrm{Ln}$ and $\mathrm{An}$ that were used to investigate inter-metal competition of $\mathrm{LanM}$. $\mathrm{Eu}^{3+}$ and $\mathrm{Cm}^{3+}$ were used as luminescence probes. 
developed highly specific synthetic chelators, for example 3,4,3-LI-1,2-HOPO, a very efficient lanthanide and actinide binder. ${ }^{[5]}$ Recent bio-inspired advances to tightly bind certain metal ions also include short peptides sequences known as lanthanide binding tags (LBT), ${ }^{[6]}$ and entirely de novo designed metalloproteins with remarkable affinities for Ln. ${ }^{[7]}$ Ten years ago, it was discovered that some bacteria also utilize Ln. These bacteria have evolved highly specific Ln uptake and Ln transport strategies. We have previously shown that even the isolated natural cofactor pyrroloquinoline quinone (PQQ) of Lndependent metalloenzymes (methanol dehydrogenases) is capable to separate $\mathrm{Ln}$ by selective precipitation. ${ }^{[8]}$ In addition to proposed small molecular weight lanthanophores, ${ }^{[9]}$ small bacterial proteins, such as Lanmodulin (LanM, Figure1), ${ }^{[9 c, 10]}$ occurring in the Ln-utilizing bacterium Methylorubrum extorquens AM1, have already shown to be excellent chelators for REE extraction. LanM is an $11.8 \mathrm{kDa}$ protein with three high affinity sites for REE binding and picomolar binding affinity for these metal ions. ${ }^{[9 a}$, 10a] Its promise as a selective extractant from electronic waste and lignite leachates has already been demonstrated by Deblonde and Cotruvo. ${ }^{[11]}$ During the preparation of this manuscript, a preprint stated that LanM is able to bind the actinide actinium with a higher affinity compared to the REE yttrium. ${ }^{[12]}$ Here, we evaluate the potential of LanM to bind the actinides $\mathrm{Np}, \mathrm{Pu}$, $\mathrm{Am}$ and $\mathrm{Cm}$ and compare the relative binding affinity ${ }^{\ddagger}$ of these actinides to each other and with the lanthanide series (Figure 1) at $\mathrm{pH} 6.7$ to mimic physiological conditions. Using time-resolved laser-induced fluorescence spectroscopy (TRLFS) in combination with the excellent luminescent properties of the two $\mathrm{f}$-block elements $\mathrm{Cm}$ and $\mathrm{Eu}$, enables inter-metal competition binding studies regarding the whole lanthanide series and selected actinides, revealing a relative affinity trend of LanM for the chosen elements.

Results and Discussion: First, $\mathrm{Eu}^{3+}$ and $\mathrm{Cm}^{3+}$ binding to LanM was evaluated with TRLFS and yielded emission spectra (after spectral deconvolution using parallel factor analysis, Figure S1). Corresponding luminescence lifetimes of $107 \mu$ s and $367 \mu$ s after excitation at $394 \mathrm{~nm}$ were determined for the $\mathrm{Eu}^{3+}$-aquo ion (purple) and $\mathrm{Eu}^{3+}-\mathrm{LanM}$ (green), respectively, with the main emission maxima at 591 and $613 \mathrm{~nm}$ (Figure 2A, 2C). The comparative analysis of the actinide LanM system provided the emission spectra of $\mathrm{Cm}^{3+}$-aquo ion (purple) and $\mathrm{Cm}^{3+-}$ LanM (green) with distinct emission maxima at 594 and $604 \mathrm{~nm}$ and lifetimes of $69 \mu \mathrm{s}$ and $198 \mu$ s after excitation at $396 \mathrm{~nm}$ Figure 2B, 2D). The luminescence lifetimes for the $\mathrm{Eu}^{3+}$-and $\mathrm{Cm}^{3+-a q u o}$ ions are in good accordance to previously reported ones and the spectral characteristics of the formed $\mathrm{Eu}^{3+-}$ and $\mathrm{Cm}^{3+-} \mathrm{LanM}$ species match reported species of the calcium-binding protein Calmodulin. ${ }^{[13]}$. Due to the greater sensitivity and quantum yields of $\mathrm{Cm}^{3+}$ 
luminescence compared to $\mathrm{Eu}^{3+},{ }^{[14]}$ a lower concentration of $18 \mathrm{nM}$ LanM and $100 \mathrm{nM} \mathrm{Cm}^{3+}$ was utilized,

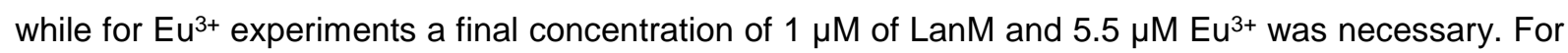
both experiments, 5.5 equivalents of $\mathrm{Eu}^{3+}$ or $\mathrm{Cm}^{3+}$ were required to obtain a $100 \%$ occupation of all 4 EF hands of LanM which also corresponded with CD experiments (Figure S3).
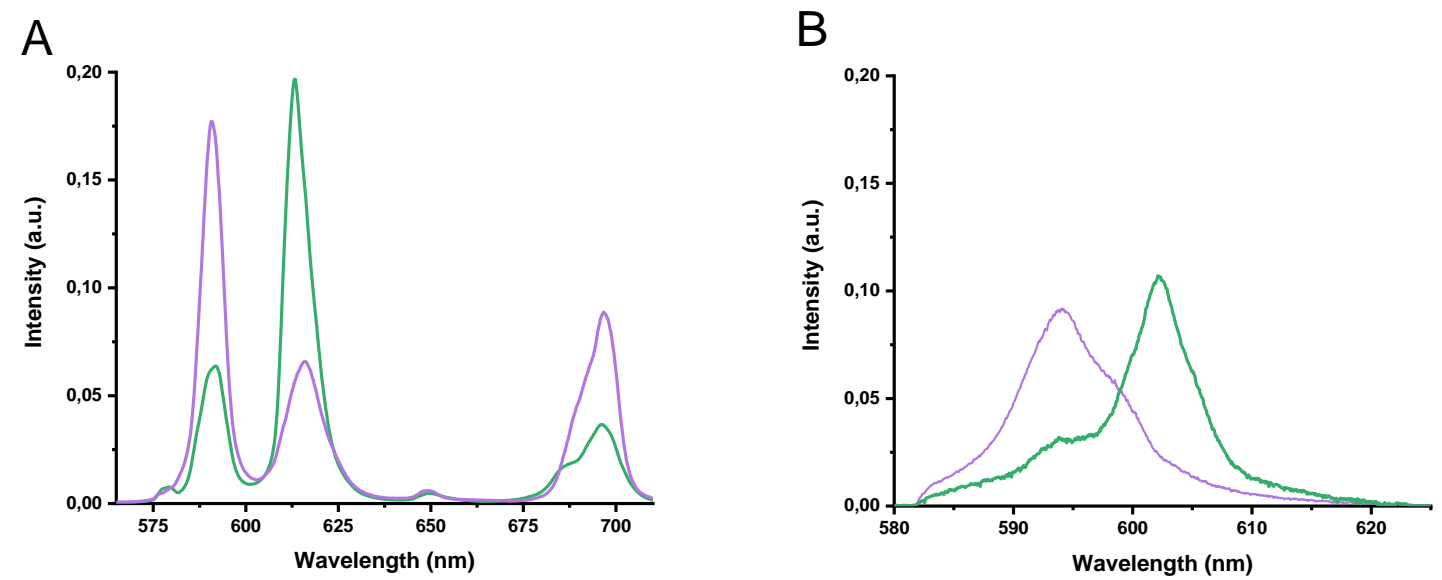

C

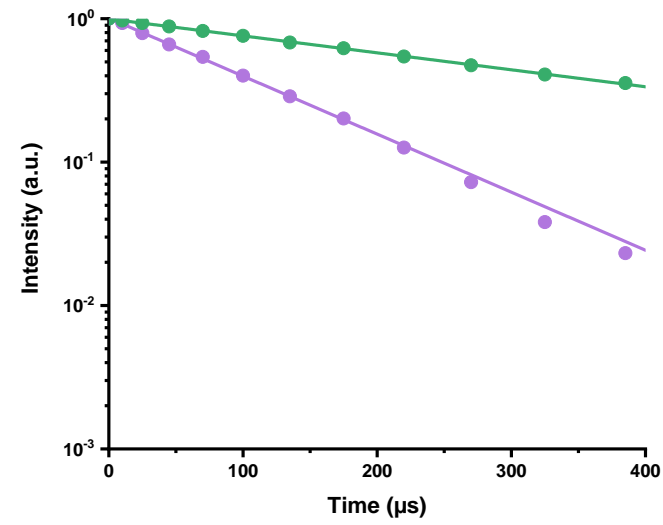

D

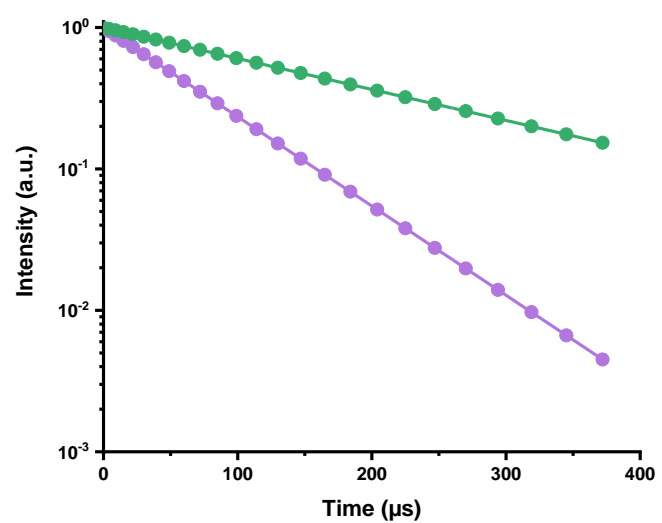

Figure 2. A Deconvoluted $\mathrm{Eu}^{3+}-\mathrm{LanM}$ and $\mathrm{Eu}^{3+}$-aquo ion spectra from TRLFS data. B Deconvoluted $\mathrm{Cm}^{3+-}$-LanM and $\mathrm{Cm}^{3+}$-aquo ion spectra from TRLFS data. $\mathbf{C}$ and $\mathbf{D}$ show the lifetime fits of the $\mathrm{Eu}^{3+}$ and $\mathrm{Cm}^{3+}$ species, respectively. Data of the $\mathrm{Ln}$-/An-aquo ions shown in purple and LanM complexes in green.

Second, for inter-metal competition studies of LanM with different Ln and An, the lanthanide series with $\mathrm{Eu}^{3+}$ and actinide series $\left(+\mathrm{Nd}^{3+}\right)$ with $\mathrm{Cm}^{3+}$ was investigated using TRLFS (Figure 1). Two different experiments were conducted for each Ln and An series. First - Ln addition - (Figure 3) where LanM (1 $\mu \mathrm{M})$ was incubated and saturated with $\mathrm{Eu}^{3+}(5.5 \mu \mathrm{M})$ for 10 minutes and then subsequently a second lanthanide $(5.5 \mu \mathrm{M})$ was added. By immediate starting of data acquisition with a continuously ascending slope by ongoing incubation time, the intensity progress of the $\mathrm{Eu}^{3+}$-LanM emission was measured within the first 50 minutes (Figure3A). In particular, with the earlier Ln (reddish to green), a still persistent decrease of the $\mathrm{Eu}^{3+}$-LanM signal was detected - while with the later $\mathrm{Ln}$ (blue to purple) such as $\mathrm{Lu}^{3+}$ a stagnating signal seemed to be already reached within the 50 minutes. After 28 hours (Figure 3B), the 
final intensity of the $\mathrm{Eu}^{3+}$-LanM complex was still remaining but had stagnated, indicating that thermodynamic equilibrium between Ln and LanM was reached. In a second experiment - Ln competition - a 1:1 mixture of $\mathrm{Eu}^{3+}$ and a second lanthanide (5.5 $\mu \mathrm{M}$ each) were premixed and added simultaneously to $1 \mu \mathrm{M}$ of LanM. Incubation for 24 hours at room temperature was chosen to ensure that the thermodynamic equilibrium had been reached and the amount of the residual Eu ${ }^{3+-L a n M}$ complex was spectroscopically determined. By spectral deconvolution of all Eu ${ }^{3+}$ LanM emission spectra, the intensity ratio of Eu ${ }^{3+}$ towards the treated second Ln was calculated (Figure 4). Based on these two experiments (Ln addition, Ln competition), we obtain two pieces of information overall: the time constants describing how fast the thermodynamic equilibrium is reached (Figure 3C) and secondly, how strong the capability is of each $\mathrm{Ln}$ to replace the Eu from the $\mathrm{Eu}^{3+}$-LanM complex representing the individual relative affinities (Figure 4). Interestingly, the obtained time constants and the relative affinities do not follow the same trend and thus the time constants are not solely determined by the relative affinity of the respective metal ions, thus other physical factors are likely at play here. Based on the time constants determination it can be concluded: the smaller the ionic radii of the $L n$, the faster the exchange against the $\mathrm{Eu}^{3+}$ in $\mathrm{Eu}^{3+}-\mathrm{LanM}$ complex. The trend correlates with the typical Ln contraction and is most likely due to a kinetic effect based only on the size and Lewis acidity of the Ln. The trend regarding the relative affinity of the formed $\mathrm{Ln}^{3+}$-LanM complex does not linearly follow the $\mathrm{Ln}$ series, but rather peaks at $\mathrm{Nd}^{3+}$, meaning that $\mathrm{Nd}^{3+}$ binds with equal relative affinity to LanM as $\mathrm{Eu}^{3+}$. It was shown recently that LanM reveals a unique, not yet described trend regarding the affinities for different Ln (Figure S2). Unfortunately, affinities for only selected Ln were reported (Table S4). While our actual data gives no absolute values of dissociation constants $K_{\mathrm{d}}$, a trend among the whole series (except $\mathrm{Pm}$ ) is clearly visible with our developed method. The $\mathrm{Ln}$ left of $\mathrm{Nd}^{3+}$ in the series bind with lower relative affinity to LanM, with $\mathrm{La}^{3+}$ occupying approximately $20 \%$ of $\mathrm{LanM}$ and $\mathrm{Eu}^{3+} 80 \%$ when added in equimolar amounts. The $\mathrm{Ln}$ to the right side of $\mathrm{Nd}^{3+}$ with smaller ionic radii as well bind less efficiently to LanM than $\mathrm{Eu}^{3+}$, with $\mathrm{Lu}^{3+}$ only $10 \%$ occupying LanM when $\mathrm{Eu}^{3+}$ is present. These results are both somewhat unexpected, but also in line what has been found for the activity of Ln-dependent methanol dehydrogenase isolated from Methylacidiphilum fumariolicum SolV. Here, adding lanthanides to a partially occupied Eu-MDH yielded the highest activity with $\mathrm{Pr}^{3+}$ and $\mathrm{Nd}^{3+}$, however, this might be just a coincidence. ${ }^{[15]}$ Despite various factors such as the gadolinium break, it has been suggested that the natural abundance of the Ln has an impact and bacterial Ln uptake and metabolism is designed to use the most abundant Ln. 
A
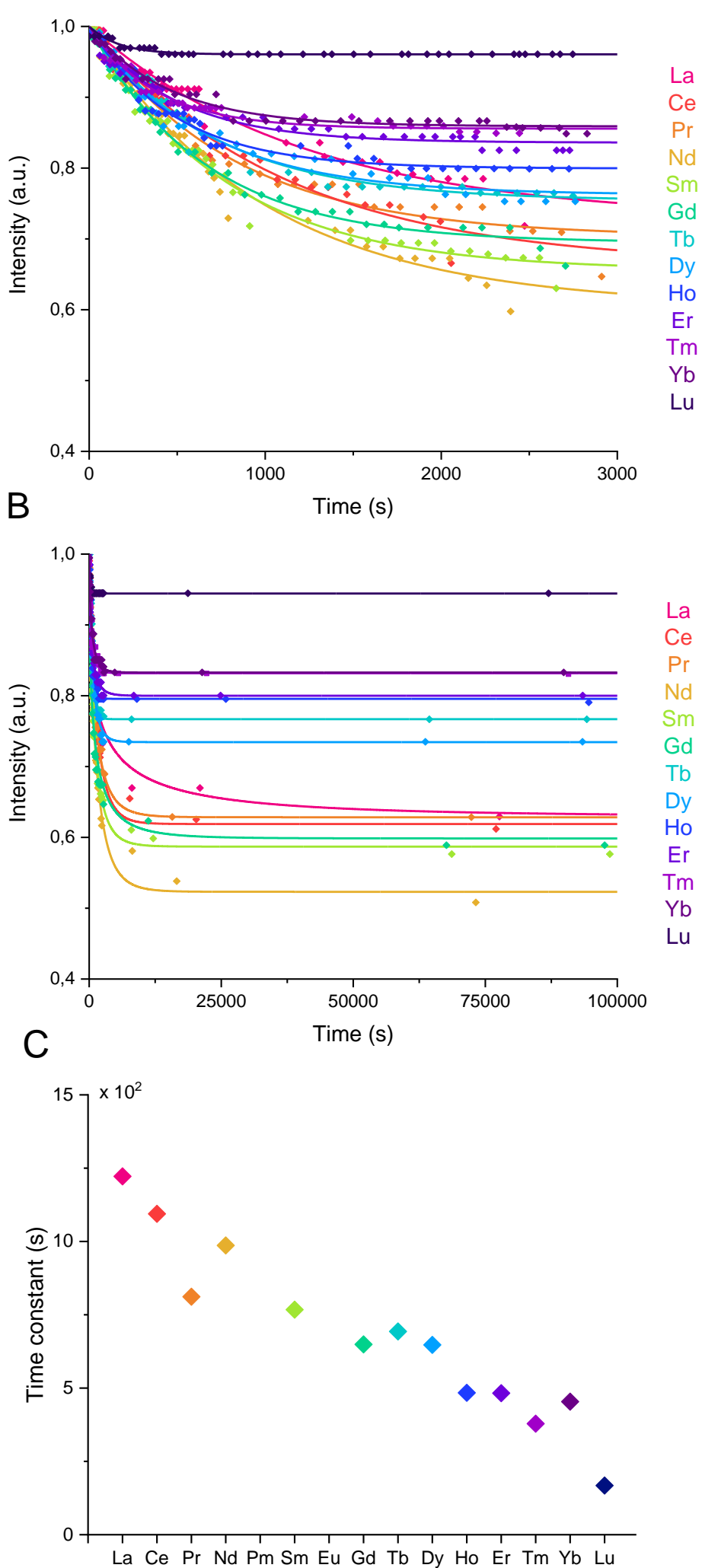

Figure 3. Lanthanide addition: A Intensity of the emission signal of the $\mathrm{Eu}^{3+}$-LanM complex within the first 50 minutes after the addition of the second lanthanide. $\mathbf{B}$ Intensity of the emission signal of the $\mathrm{Eu}^{3+}$-LanM complex up to 28 hours after addition of the second lanthanide. C Fitted time constants across the Ln series based on B. 


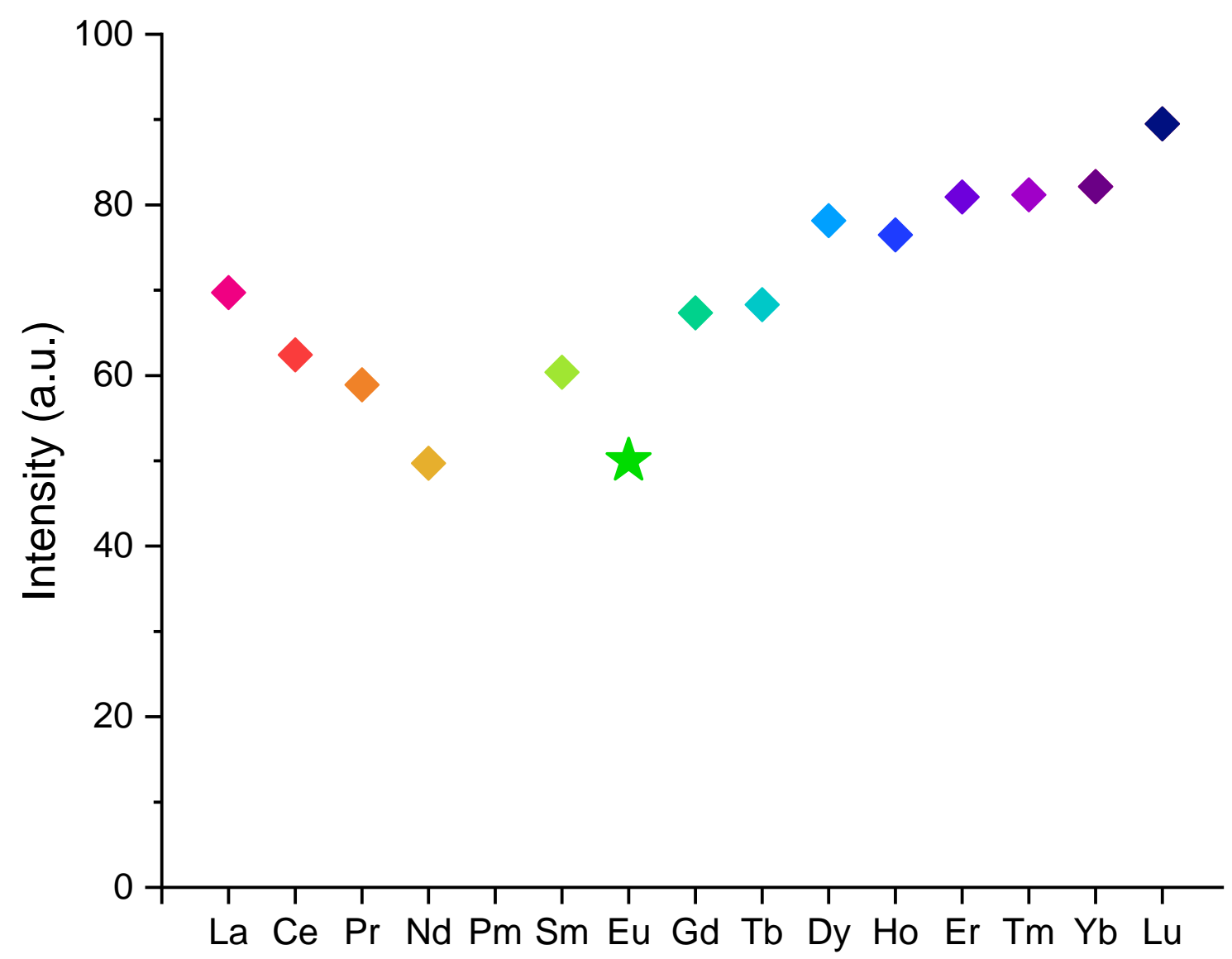

Figure 4. Lanthanide competition: Final intensity of the $\mathrm{Eu}^{3+}$-LanM-complex emission after 24 hours and prior to simultaneous addition of a second lanthanide and $\mathrm{Eu}^{3+}$. The green star data point was added for clarity and indicates and intensity of $50 \%$ of the $\mathrm{Eu}^{3+}$-LanM complex.

After having experimentally verified that $\mathrm{Nd}^{3+}$ binds equally well as $\mathrm{Eu}^{3+}$ to $\mathrm{LanM}$ in our two lanthanide binding studies, we put forward this competitive approach for four trivalent actinides. The trivalent actinides $-\mathrm{Np}^{3+}, \mathrm{Pu}^{3+}, \mathrm{Am}^{3+}, \mathrm{Cm}^{3+}$ - were chosen to compete with $\mathrm{Nd}^{3+}$ as the strongest opponent of lanthanides for the LanM relative binding affinity. $\mathrm{Cm}^{3+}$ was used as comparable luminescence probe for the inter-metal competition studies. In the first experiment - An addition - LanM (18 nM) was added to $\mathrm{Cm}^{3+}(100 \mathrm{nM})$ and after $10 \mathrm{~min}$, the equilibrated solution was treated with either $\mathrm{Nd}^{3+}, \mathrm{Np}^{3+}, \mathrm{Pu}^{3+}$ or $\mathrm{Am}^{3+}\left(100 \mathrm{nM}\right.$, Figure 5). By monitoring the $\mathrm{Cm}^{3+}$ luminescence, the reduction of the $\mathrm{Cm}^{3+}$-LanM intensity over time was clearly visible with a faster leveling for $\mathrm{Np}^{3+}$ and $\mathrm{Pu}^{3+}$ than for $\mathrm{Nd}^{3+}$ and $\mathrm{Am}^{3+}$ (Figure 5A, 5B). To obtain a clear picture of the thermodynamic equilibrium (An competition), equimolar amounts (100 nM each) of $\mathrm{Cm}^{3+}$ and respectively $\mathrm{Nd}^{3+}, \mathrm{Np}^{3+}, \mathrm{Pu}^{3+}$ or $\mathrm{Am}^{3+}$ were added to $\mathrm{LanM}$ and the intensity of $\mathrm{Cm}^{3+}$-LanM complex were measured after 24 hours of incubation (Figure 6). In the actinide experiments we observe clearly two groups based on time constants (Figure $5 \mathrm{C}$ ) and on the amount of $\mathrm{Cm}^{3+-}$ LanM complex in equilibrium (Figure 6): $\mathrm{Nd}-\mathrm{Am}$ and $\mathrm{Np}-\mathrm{Pu}$. The results show that the actinide 
A

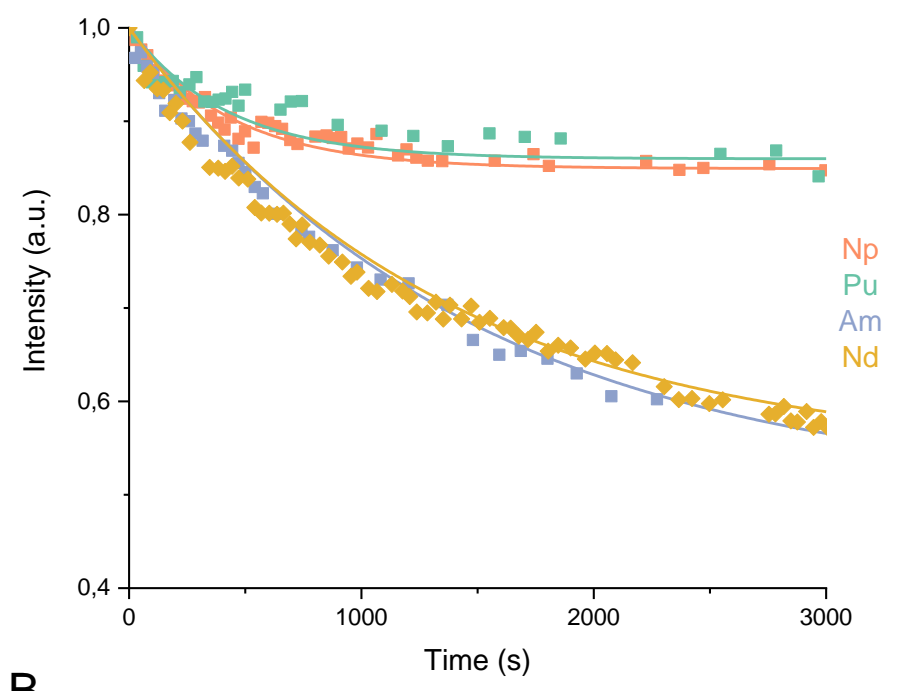

B

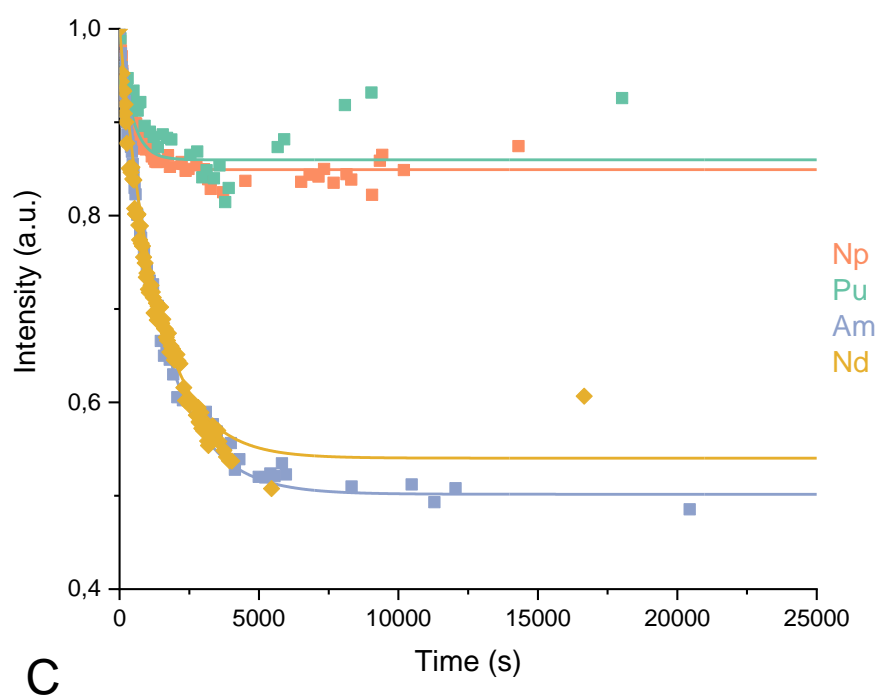

C

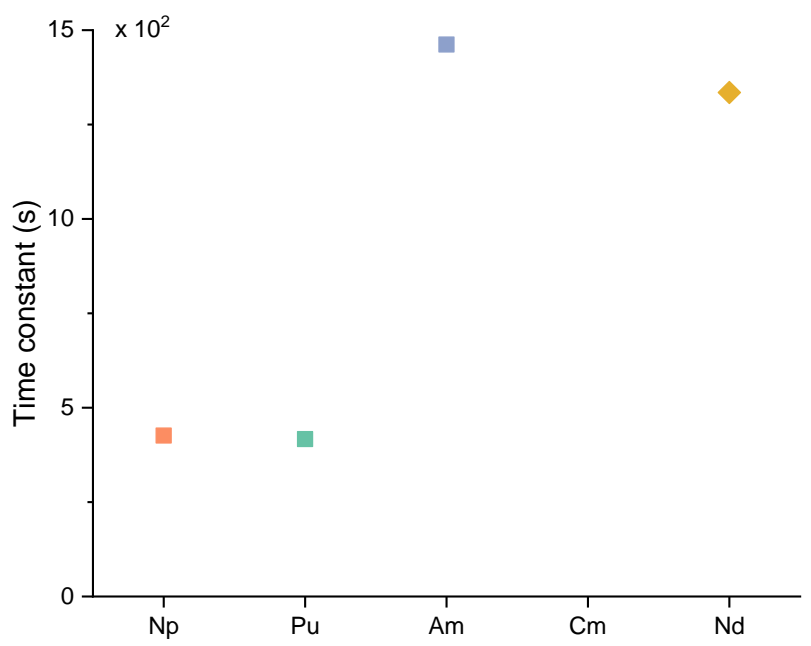

Figure 5. Actinide addition: A Intensity of the emission signal of the $\mathrm{Cm}^{3+}$-LanM complex within the first 50 minutes after the addition of the second actinide or $\mathrm{Nd}^{3+}$. B Intensity of the emission signal of the $\mathrm{Cm}^{3+}$-LanM complex up to 7 hours after addition of the second actinide or $\mathrm{Nd}^{3+}$. C Fitted time constants based on $\mathrm{B}$. 


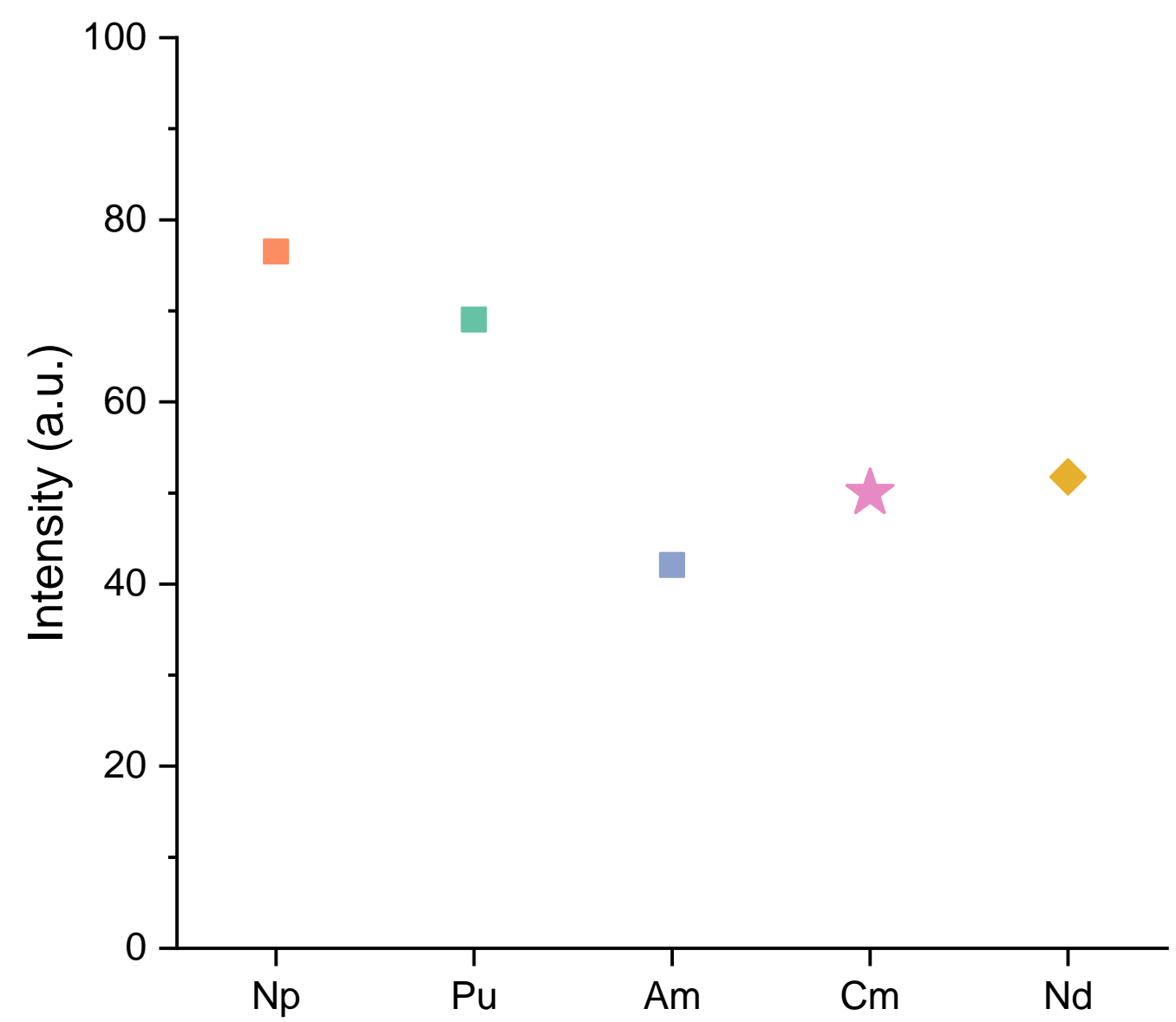

Figure 6. Actinide competition: Residual intensity of the $\mathrm{Cm}^{3+}$ emission after 24 hours and prior simultaneous addition of $\mathrm{Nd}^{3+}$, $\mathrm{Am}^{3+}, \mathrm{Pu}$ or $\mathrm{Np}$, respectively. The data point pink star was added for clarity and indicates and intensity of $50 \%$ of the $\mathrm{Cm}^{3+}-\mathrm{LanM}^{\mathrm{N}}$ complex.

$f$-block elements reveal similar relative binding affinities to LanM like that of the Ln f-block elements, which repeatedly underlines their chemical analogy. Secondly, Np and Pu display a smaller relative binding affinity to LanM compared to $\mathrm{Cm}^{3+}$, however an exchange of $\mathrm{Cm}^{3+}$ with the added actinide is observable, since the intensity of the $\mathrm{Cm}^{3+}$-LanM complex is distinctly reduced. The initial oxidation state of $\mathrm{Np}$ and $\mathrm{Pu}$ was + III, but $\mathrm{Np}$ and $\mathrm{Pu}$ reveal a manifold redox chemistry under certain conditions (Table S3). In aqueous solution, $\mathrm{Np}$ is mainly present in +III to + VII with the most stable pentavalent dioxo form $\mathrm{NpO}_{2}{ }^{+}$, while for $\mathrm{Pu}$, a co-existence in equilibrium of four different oxidation states from +III to $+\mathrm{VI}$ has been reported. ${ }^{[16]}$ Due to the more versatile redox chemistry of $\mathrm{Np}$ and $\mathrm{Pu}$ the oxidation to the penta- and hexavalent actinyl $\left(\mathrm{AnO}_{2}{ }^{+}\right.$and $\left.\mathrm{AnO}_{2}{ }^{2+}\right)$ structures described with trans-dioxo structure $\left(\mathrm{O}_{\mathrm{ax}}=\mathrm{An}(+\mathrm{V} / \mathrm{VI})=\mathrm{O}_{\mathrm{ax}}\right)$ are easily conceivable. The oxidation state most probably changed by varying the chemical environment of $\mathrm{Np}$ and $\mathrm{Pu}$ by dilution, as a function of the aqueous speciation or interaction with complexing agent. To examine the final oxidation state of $\mathrm{Np}$ and $\mathrm{Pu}$ in the nanomolar concentration range after the incubation with LanM, no spectroscopic method is available. Reflecting the determined 
time constants for $\mathrm{Np}$ and $\mathrm{Pu}$, LanM binds $\mathrm{Np}^{3+}$ and $\mathrm{Pu}^{3+}$ with lower relative affinities, comparable to the later, or very early Lns. In contrast, trans-dioxo cation binding might be not able to effectively bind to LanM. Thirdly and surprisingly, the trivalent $f$-block element $\mathrm{Am}^{3+}$ owns a higher relative affinity to LanM than $\mathrm{Cm}^{3+}$ while $\mathrm{Nd}^{3+}$ and $\mathrm{Cm}^{3+}$ bind very similar. The high relative binding affinity is most probably due to the same most stable oxidation states and ionic radii of the metal ions (Table S2). $\mathrm{Am}^{3+}$ and $\mathrm{Cm}^{3+}$ are both stable in the preferred + III oxidation state and have ionic radii that strongly resemble $\mathrm{Nd}^{3+}{ }^{[17]} \mathrm{A}$ direct comparison between the $\mathrm{Eu}^{3+}$ and $\mathrm{Cm}^{3+}$ systems and experimental setups is ambitious. For the $\mathrm{Cm}^{3+}$ experiments, the concentrations were 50 times lower, and dilution effects, solubility, hydrolysis or carbonate complexation of $\mathrm{Ln} / \mathrm{An}$, as well as parameters affecting the kinetics, should only interfere (if at all) with minor contribution. To be able to draw a comparison between both $\mathrm{Ln}^{3+}-\mathrm{LanM}$ and $\mathrm{An}{ }^{3+-} \mathrm{LanM}$ studies, $\mathrm{Nd}^{3+}$ was chosen for both setups, enabling an estimation of relative affinity for all selected Lns and $\mathrm{Ans}$. $\mathrm{Nd}^{3+}$ was the best of the $\mathrm{Ln}$ series besides $\mathrm{Eu}^{3+}$ to bind to $\mathrm{LanM}$, but $\mathrm{Am}^{3+}$ displayed an even higher relative binding affinity with a faster exchange rate. Finally, with all things considered and under the conditions chosen, LanM, a natural lanthanide-binding protein, favors an actinide over the lanthanides. In addition, we display a unique relative affinity trend of LanM for the Ln series which will also help in the future to develop new innovative bio-inspired strategies for lanthanide or actinide recycling and separation. In addition, an easy and versatile method was developed, using $\mathrm{Eu}^{3+}$ and $\mathrm{Cm}^{3+}$ as comparative luminescence probe, for inter-metal competition studies regarding lanthanides and selected actinides and their binding to biological molecules.

\footnotetext{
" Here we use the term relative binding affinity, because absolute values cannot be obtained from the competition experiment performed. This relative binding affinity is based on comparing the average affinities of all LanM EF-hands for different lanthanides and actinides under given conditions.
}

Acknowledgements: LJD acknowledges a grant from the Klaus-Tschira Boost Fund and support from the ERC Starting grant Lanthanophore.

\section{References:}

[1] a) T. Cheisson, E. J. Schelter, Science 2019, 363, 489-493; b) V. Balaram, Geosci. Front. 2019, $10,1285-1303$.

[2] a) F. Xie, T. A. Zhang, D. Dreisinger, F. Doyle, Miner. Eng. 2014, 56, 10-28; b) A. Jordens, Y. P. Cheng, K. E. Waters, Miner. Eng. 2013, 41, 97-114. 
[3] a) G. Ambaye, M. Vaccari, F. D. Castro, S. Prasad, S. Rtimi, Environ. Sci. Pollut. R. 2020, 27, 36052-36074; b) R. C. Smith, R. K. Taggart, J. C. Hower, M. R. Wiesner, H. Hsu-Kim, Environ. Sci. Technol. 2019, 53, 4490-4499.

[4] a) A. V. Gelis, P. Kozak, A. T. Breshears, M. A. Brown, C. Launiere, E. L. Campbell, G. B. Hall, T. G. Levitskaia, V. E. Holfeltz, G. J. Lumetta, Sci. Rep. 2019, 9, 12842; b) N. P. Bessen, J. A. Jackson, M. P. Jensen, J. C. Shafer, Coordi. Chem. Rev. 2020, 421, 213446.

[5] a) A. S. Ivanov, B. F. Parker, Z. Zhang, B. Aguila, Q. Sun, S. Ma, S. Jansone-Popova, J. Arnold, R. T. Mayes, S. Dai, V. S. Bryantsev, L. Rao, I. Popovs, Nat. Commun. 2019, 10, 819; b) R. J. Abergel, P. W. Durbin, B. Kullgren, S. N. Ebbe, J. Xu, P. Y. Chang, D. I. Bunin, E. A. Blakely, K. A. Bjornstad, C. J. Rosen, D. K. Shuh, K. N. Raymond, Health Phys. 2010, 99, 401-407.

[6] T. Hatanaka, N. Kikkawa, A. Matsugami, Y. Hosokawa, F. Hayashi, N. Ishida, Sci. Rep. 2020, 10, 19468.

[7] a) S. J. Caldwell, I. C. Haydon, N. Piperidou, P.-S. Huang, M. J. Bick, H. S. Sjöström, D. Hilvert, D. Baker, C. Zeymer, Proc. Natl. Acad. Sci. U.S.A. 2020, 117, 30362; b) J. A. Mattocks, J. L. Tirsch, J. A. Cotruvo, in Methods Enzymol., Vol. 651 (Ed.: J. A. Cotruvo), Academic Press, 2021, 23-61.

[8] H. Lumpe, A. Menke, C. Haisch, P. Mayer, A. Kabelitz, K. V. Yusenko, A. Guilherme Buzanich, T. Block, R. Pöttgen, F. Emmerling, L. J. Daumann, Chem. Eur. J. 2020, 26, 10133-10139.

[9] a) J. A. Cotruvo, Jr., ACS Cent. Sci. 2019, 5, 1496-1506; b) L. J. Daumann, Angew. Chem. Int. Ed. 2019, 58, 12795-12802; c) A. M. Ochsner, L. Hemmerle, T. Vonderach, R. Nüssli, M. Bortfeld-Miller, B. Hattendorf, J. A. Vorholt, Mol. Microbiol. 2019, 111, 1152-1166.

[10] a) J. A. Cotruvo, E. R. Featherston, J. A. Mattocks, J. V. Ho, T. N. Laremore, J. Am. Chem. Soc. 2018, 140, 15056-15061; b) E. C. Cook, E. R. Featherston, S. A. Showalter, J. A. Cotruvo, Jr., Biochemistry 2019, 58, 120-125.

[11] G. J. P. Deblonde, J. A. Mattocks, D. M. Park, D. W. Reed, J. A. Cotruvo, Y. Jiao, Inorg. Chem. 2020, 59, 11855-11867.

[12] G. Deblonde, J. A. Mattocks, Z. Dong, P. T. Wooddy, J. A. J. Cotruvo, M. Zavarin, ChemRxiv 2021, DOI 10.26434/chemrxiv.14763426.v1. This content is a preprint and has not been peer-reviewed. 
[13] a) B. Drobot, M. Schmidt, Y. Mochizuki, T. Abe, K. Okuwaki, F. Brulfert, S. Falke, S. A. Samsonov, Y. Komeiji, C. Betzel, T. Stumpf, J. Raff, S. Tsushima, Phys. Chem. Chem. Phys. 2019; b) C. Wilke, A. Barkleit, T. Stumpf, A. Ikeda-Ohno, J. Inorg. Biochem. 2017, 175, 248258.

[14] C. Moulin, P. Decambox, P. Mauchien, J. Radioanal. Nucl. Ch. 1997, 226, 135-138.

[15] H. Lumpe, A. Pol, H. J. M. Op den Camp, L. J. Daumann, Dalton Trans. 2018, 47, 10463-10472.

[16] L. R. Morss, N. M. Edelstein, J. Fuger, J. J. Katz, L. Morss, The chemistry of the actinide and transactinide elements, Vol. 1, Springer, 2006.

[17] G. T. Seaborg, D. E. Hobart, Summary of the properties of the lanthanide and actinide elements, Indian Association of Nuclear Chemists and Allied Scientists, India, 1996. 